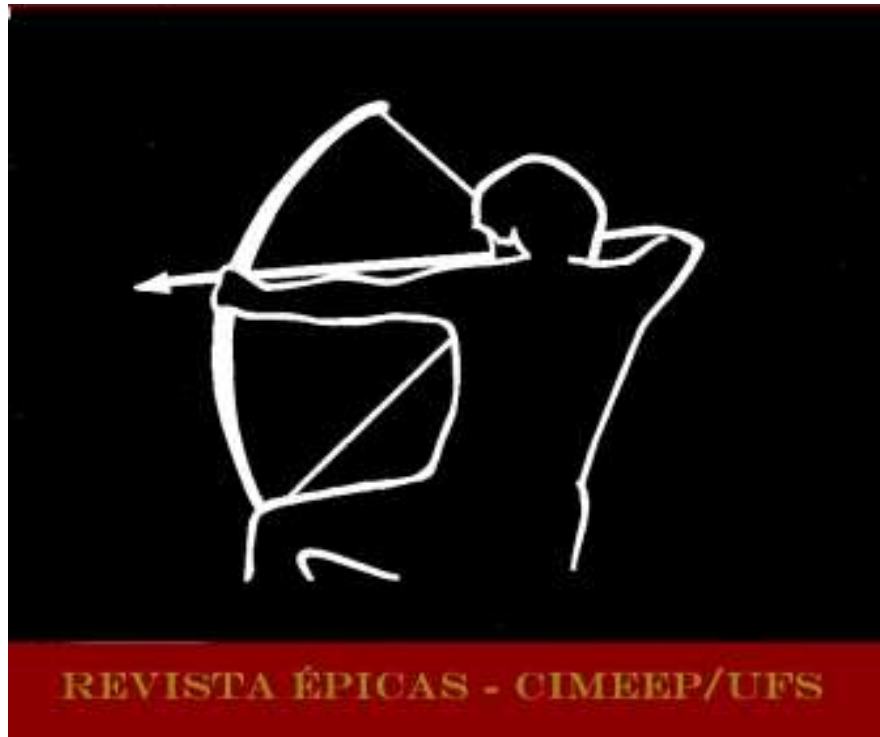

SANTOS, Jânio Vieira dos; ANDRADE, Alexandre de Melo. Alma Vênus, de Marco Lucchesi, e o diálogo com A divina comédia. In: Revista Épicas. Ano 5, Número Especial 4, Fev 2021, p 119-131. ISSN 2527080X. DOI: http://dx.doi.org/10.47044/2527-080X.2021vNE4.119131

\title{
ALMA VÊNUS, DE MARCO LUCCHESI, E O DIÁLOGO COM A DIVINA COMÉDIA ${ }^{1}$ ALMA VÊNUS, BY MARCO LUCCHESI, AND THE DIALOGUE WITH THE DIVINE COMEDY
}

\author{
Jânio Vieira dos Santos ${ }^{2}$ \\ Alexandre de Melo Andrade ${ }^{3}$
}

RESUMO: O presente trabalho buscou abordar o diálogo entre o clássico dantesco e a poesia contemporânea brasileira, mais especificamente com o poeta carioca Marco Lucchesi, como forma de aproximar o clássico do contemporâneo, em suas familiaridades. Utilizamos da literatura comparada como ferramenta imprescindível no tocante à compreensão e identificação dos pontos ressonantes em obras e poetas diferentes, e o modo como a literatura é transformada ou transfigurada dentro de visões múltiplas, mas que se familiarizam na ideia do humano, da inquietação, da procura por sentidos. Dessa forma, dedicamos nossa atenção aos pontos comuns entre as duas obras literárias estudadas, perpassando pela filosofia, a crítica e a teoria literárias, no intuito de proporcionar uma discussão entre o clássico e o contemporâneo de modo objetivo e claro. Tratamos, com isso, de discutir a importância da Divina Comédia na contemporaneidade através do cotejamento da mesma com a obra Alma Vênus (2000), do poeta brasileiro Marco Lucchesi.

Palavras-chave: A Divina Comédia. Poesia. Literatura comparada. Marco Lucchesi.

ABSTRACT: The present work sought to approach the dialogue between the dantesque classic and contemporary brazilian poetry, more specifically with the carioca poet Marco Lucchesi, as a way of bringing the classic and the contemporary, in their familiarities. We use comparative literature as an essential tool in terms of understanding and

\footnotetext{
${ }^{1}$ Este texto é fruto do desenvolvimento do plano de trabalho "Ressonância de A divina comédia no Brasil do século XXI" (pertencente ao projeto de iniciação científica "Ressonâncias de A divina comédia no Brasil"), orientado pelo Prof. Dr. Alexandre de Melo Andrade, no período compreendido entre agosto de 2019 e julho de 2020.

${ }^{2}$ Graduando em letras português pela Universidade Federal de Sergipe - UFS. Email: janio.vieira16@gmail.com. ORCID: https://orcid.org/0000-0001-7093-4958.

${ }^{3}$ Doutor em Estudos Literários. Professor Adjunto do Departamento de Letras Vernáculas, do Programa de Pós-Graduação em Letras e do PROFLETRAS, da UFS. Email: alexandremelo06@uol.com.br. ORCID: http://orcid.org/0000-0002-8467-607X.
} 
identifying the resonant points in different works and poets, and the way that literature is transformed or transfigured within multiple views, but that are familiarized with the idea of the human, of restlessness, of search for directions. In this way, we dedicate our attention to the common points between the two literary works studied, going through philosophy, criticism and literary theory, in order to provide an objective and clear discussion between the classic and the contemporary. With this, we tried to discuss the importance of Divine Comedy in contemporary times by comparing it with the work Alma Vênus (2000), by the brazilian poet Marco Lucchesi.

Keywords: The Divine Comedy. Poetry. Comparative literature. Marco Lucchesi.

\section{Introdução}

As ideias filosóficas discutidas pelos neoclássicos da antiguidade nos proporcionam amplas discussões em torno da contemporaneidade, tornando-se temas que perpassam o tempo e que são bastante atuais e pertinentes no tocante aos estudos das humanidades. Ao lermos o Tratados das Enéadas (2000), de Plotino, e nos depararmos com questões sobre o Uno, o Belo, o Amor, entre outras abordagens, compreendemos que o clássico de algum modo traz significado aos contemporâneos.

O que Plotino nos apresenta nesses tratados tem grande contribuição para os escritores, em especial os clássicos. É importante dizer que o clássico nos humaniza, há nele toda uma construção do humano, desde a virtude ao vício. E toma força com o passar do tempo. Força essa que é essencial à consciência do Ser. Seja por conta do diálogo que mantém com a natureza das coisas através da filosofia, seja através da manipulação com a palavra.

Pudemos perceber ideias de Plotino na obra-prima de Dante Alighieri, A Divina comédia. Obra que narra a trajetória do poeta, vivo, pelos reinos transcendentais em direção à luz.

Dante Alighieri nasceu "[...] na primavera de 1265, fluido o mês de maio, numa modesta casa que o serventuário de justiça Alighieri e sua esposa dona Bela possuíam junto à porta de São Pedro." (MARTINS, 1984, p. 27) e foi escritor, poeta e político florentino. É considerado o maior poeta da língua italiana. Apaixonou-se, ainda jovem (um amor platônico) por Beatriz Portinari, que foi sua musa inspiradora e a responsável por guiá-lo ao Paraíso. Era adepto aos ensinamentos de São Tomás de Aquino e estudioso da filosofia escolástica de seu tempo; apoiado nessas lições, Dante escreve A Divina comédia, poema dividido em três partes: Inferno, Purgatório e Paraíso, composto de cem cantos e totalizando 14.233 versos. Expulso de sua terra natal e condenado ao exílio, Dante morre aos 56 anos, no dia 13 de setembro 1321, em Ravena.

O nosso artigo inteirou-se de abordar os diálogos entre A Divina comédia, com a poesia contemporânea brasileira, mais especificamente a obra Alma Vênus (2000), do poeta carioca Marco Lucchesi. Para isso, utilizamos como base teórica a literatura comparada, como meio de entendermos esse processo de construção literária. Nesse sentido, utilizamos, além de materiais literários, outros textos teóricos e críticos, como forma de perceber e dissertar sobre as ressonâncias da Divina comédia no livro de poemas supracitado.

O autor de Alma Vênus, Marco Americo Lucchesi, nasceu em 9 de dezembro de 1963, no Rio de Janeiro. Poeta, romancista, memorialista, ensaísta, tradutor e editor. Além de escritor premiadíssimo, Marco 
Lucchesi traduziu diversos autores. É conhecedor de mais de vinte idiomas e criador de uma língua artificial denominada "laputar". É professor titular de Literatura Comparada na Faculdade de Letras da Universidade Federal do Rio de Janeiro (UFRJ), formado em História pela Universidade Federal Fluminense (UFF), recebendo os títulos de Mestre e Doutor em Ciências da Literatura, pela UFRJ, e com pós-doutorado em Filosofia da Renascença pela Universidade de Colômbia, na Alemanha. Seus livros foram traduzidos para o árabe, romeno, italiano, inglês, francês, alemão, espanhol, persa, russo, turco, polonês, hindi, sueco, húngaro, urdu, bangla e latim.

O escritor carioca é o sétimo ocupante da cadeira № 15 da Academia Brasileira de Letras (ABL), presidindo a casa desde 2018. É um dos grandes estudiosos da obra de Dante Alighieri no Brasil e, em sua literatura Lucchesi nos apresenta, de forma poética, um universo vasto, passando pela história, filosofia, matemática, entre outras vertentes. No prefácio de A paixão do infinito (1994), o escritor Antônio Carlos Villaça diz que "A vocação intelectual de Marco Americo Lucchesi é das mais poderosas que tenho conhecido. E ele une admiravelmente erudição e sensibilidade, ensaísmo e poesia." (VILLAÇA, 1994, p. 15). Em Alma Vênus, livro de poemas publicado em 2000, o autor passeia pela literatura clássica, em meio a Dante e Camões, tecendo com palavras a busca de algo que esteja além da condição imanente do homem. Trata-se de "Uma poesia reveladora da sede insaciável de apreensão do sentido maior da existência, em busca do Absoluto. Em busca de Deus. E, mais que tudo, de si mesmo." (PROENÇA FILHO, 2006, p. 17-18).

Sua obra carrega o verdadeiro espírito dos clássicos. Nela, Lucchesi estabelece diálogos com Plotino, Platão, Aristóteles e, em especial, Dante. O poeta traz a visão de um futuro que se busca e de um passado para o qual deseja retornar, unindo duas pontas opostas no intento de alcançar o todo.

\section{Alma Vênus e a busca pelo eterno retorno}

A primeira epígrafe que abre o livro Alma Vênus, de Marco Lucchesi, dialoga profundamente com Plotino, no que diz respeito ao Uno (Tratados das Enéadas) e, em especial, com A Divina Comédia, de Dante Alighieri. E quando Lucchesi nos apresenta a epígrafe "Uma inteligência que compreenda / todas as forças que agem na natureza...", de Laplace, está nos apresentando, antecipadamente, a viagem que nos espera em Alma Vênus.

Na obra-prima do poeta florentino, sua viagem pelo Inferno, Purgatório e Paraíso é em direção ao Uno, à inteligência suprema. Dante inicia sua viagem pelo Inferno escuro, passando pelo Purgatório, e terminando no Paraíso, onde há luz intensa.

Lucchesi divide seu livro em quatros partes, cada uma apresentando epígrafes que dialogam entre si e com os poemas que cada uma compõe, e, assim como Dante, empreende uma viagem que ocorre por entre as horas do dia em direção à luz. 
Em "Princípios", primeira parte do livro, Lucchesi nos apresenta uma epígrafe de Guimarães Rosa que nos remete a uma busca infinita: "Tudo, para mim, é viagem de volta". É como se ao chegar ao fim o poeta se desse conta de que ainda não é o fim, fazendo um retorno. Uma imagem cíclica que cresce a cada vez que o poeta mergulha na busca do que procura. A procura pelo princípio e futuro. O poeta, em entrevista a Floriano Martins, quando indagado sobre como pensa no futuro, responde:

Com saudades. Saudades do futuro. Saudade do ainda-não. Mesmo que no passado. A volta de Guimarães Rosa como a volta ao primordial, fora do tempo e do espaço. A demanda de Ítaca e do tempo mítico. [...] Fascina-me a ideia do eterno retorno. E de modo ambíguo. Porque ao mesmo tempo que me atrai também me assusta. Outra concepção, a do físico Mario Novello, com suas viagens no tempo. Viagens não convencionais: no papel, nos cálculos. Mas viagem. Nas curvas de tempo fechado. Na herança das cogitações de Gödel. Isso tudo em Alma Vênus, que é um livro temperado por questões cósmicas, em cujas águas tentei elaborar como paródia um microlusíadas quântico, marcado por elementos de retorno [...], e observações cosmológicas [...] e o problema da matéria [...] (LUCCHESI, 2009, p. 264; grifos do autor).

Lucchesi apresenta nessa primeira parte quatro poemas: "Alef", "Bet", "Ghimel" e "Dalet", iniciais do alfabeto grego que, de certa forma, nos remetem à origem. Como nos afirma Alexandre de Melo Andrade:

"Alef" remete ao início, ponto que contém todo o universo; "Bet" refere-se à deusa da fertilidade; "Ghimel" representa um ideograma primitivo, geratriz das coisas espirituais, manifestação do Divino; e "Dalet", por sua vez, seria o conjunto de rios e terrenos que formam canais até o mar. (ANDRADE, 2012, p. 113; aspas do autor).

Também não podemos desconsiderar o início da palavra. A forma como o poeta usa da linguagem para ampliar suas vivências. Percebemos isso nas epígrafes da segunda e terceira partes, intituladas de "Temporais" e "Horizontes", respectivamente: "while they expected the descent / of the tardy Angel, the doors were broken...", do historiador inglês Gibbon, e a terceira, "Ti perdo, ti rintraccio, / ti perdo ancora, mio luogo, / non arrivo a te.", do poeta italiano Mario Luzi. Fazendo uso de diferentes línguas, Lucchesi universaliza, de certo modo, a viagem de uma procura de sentidos múltiplos e infinitos.

Percebemos que a quarta e última epígrafe, "Sinto que vou voltar-me para Ti", de Jorge de Sena, dialoga com a primeira, de Guimarães Rosa. Ambas no sentido de um fechamento cíclico proposto pelo poeta em sua viagem, que não se abre nem se fecha.

Em Alma Vênus nos deparamos com a busca de algo que ainda não é. Há uma retomada às origens, tanto do objeto desejado, quanto do Ser. Nessa viagem o eu lírico está rodeado da matéria, dos elementos que Ihes servem de motivação. Uma motivação ainda indefinida.

Vênus, que é na mitologia romana a Deusa do amor e da beleza, possuía um olhar vago, porém seus olhos eram o ideal da beleza; e é também o nome do planeta Vênus, conhecido como estrela Dalva, estrela da manhã, estrela da tarde e joia do céu. Ainda absorvendo a ideia desses significados, compreendemos que a estrela é o símbolo para guia da viagem empreendida pelo poeta. Nesse sentido, podemos interpretar esses 
elementos, trazidos por Lucchesi, como referências à obra de Dante; os olhos que são a fonte da angústia do poeta florentino pelo Inferno e de contemplação da luz no Paraíso, e estrela, a viagem por ele empreendida nos reinos infernal e celeste.

Na primeira parte de Alma Vênus, o poeta carioca dialoga frequentemente com Plotino, no que diz respeito ao Uno. A busca pela Unidade empreende o início da viagem lucchesiana. Há uma espécie de espera projetada no uso da forma verbal "virá", no futuro do presente:

\author{
Alef \\ Virá \\ de algum lugar \\ perdido \\ virá \\ de um fosco \\ desabrigo \\ de frios \\ roseirais \\ de medos \\ ancestrais \\ virá \\ no assombro \\ do poema \\ virá \\ na forma \\ de uma anêmona \\ da funda \\ superfície \\ dos olhos \\ do deserto \\ virá \\ das níveas \\ afluências \\ no sal \\ das confluências \\ virá \\ de um verbo \\ reticente \\ de um novo \\ continente
}




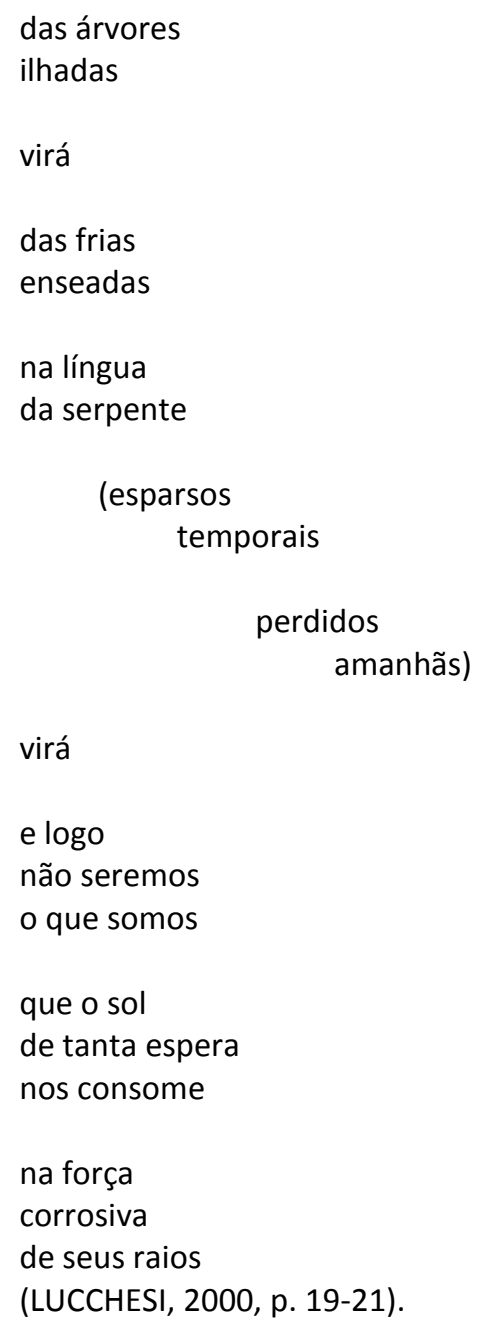

Há uma dualidade entre finitude $\mathrm{x}$ infinitude, depositada nos versos desse poema, entre o que é e o que não é. O "virá" nos leva ao futuro, a uma viagem que não tem fim por ser incerta. Mas ao mesmo tempo que vai dando ritmo a essa viagem, o poeta une esse futuro com o passado e o presente. O que "virá" está cercado do que já foi e do que ainda é. O "virá" também nos causa a impressão de viagem, locomoção. Como se o dito anteriormente sofresse uma nova transformação e fosse outro, e outro, e outro constante, e causanos a sensação de já termos iniciado a viagem. A ideia de início está presente no título do poema "Alef": primeira letra do alfabeto grego. Início, nesse caso, da linguagem. A repetição do verbo "virá" oito vezes, número que representa o domínio da matéria e, quando deitado, simboliza o infinito, mostra-nos essa dualidade presente no poema. Além de nos fazer lembrar de Virgílio e Beatriz, guias de Dante na Divina comédia, que vieram ao seu encontro para salvá-lo. Aqui, Lucchesi une o futuro (intangível), conjugando a forma verbal "virá" com os elementos da natureza (tangível).

Percebemos em "Bet", segundo poema dessa primeira parte, o diálogo com a filosofia neoclássica. Nas cinco primeiras estrofes temos: 


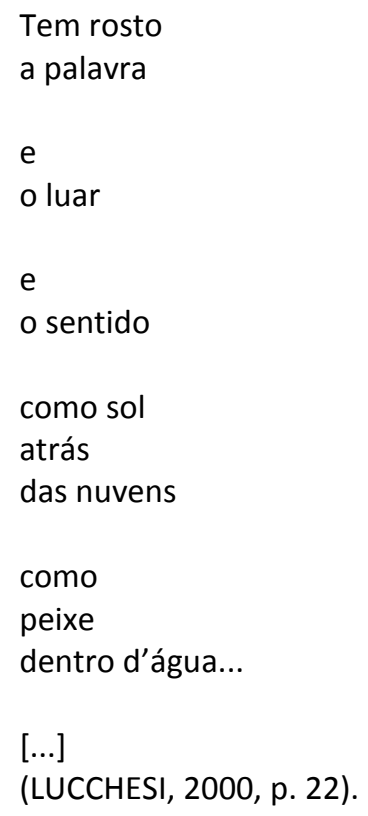

O poeta constrói camadas usando as conjunções aditivas " $\mathrm{e}$ " e "como" para unir os elementos metafísicos ("luar", "sentido", "sol" e "nuvens") e os naturais ("peixes" e "águas"), criando uma espécie de rosa. O próprio poeta disse em entrevista a Floriano Marins: "A minha paixão tem sido a de conjugar as partes quebradas de um diálogo. E tenho como certo que a cidadania vem dos âmbitos de uma conversa toda marcada de adição. Não quero 'ou'. Quero 'e'." (LUCCHESI, 2009, p. 262; aspas do autor). Essa preocupação com o Todo, buscando-se a unidade, é o que Plotino discorre sobre o belo: "Quando algo é conduzido à unidade, a beleza entroniza-se ali, pois ela se difunde por cada uma de suas partes individualmente e pelo conjunto." (PLOTINO, 2000, p. 22-23). Faz-se, assim, alusão à construção de uma imagem múltipla, infinita e ao mesmo tempo conjunta.

Essa mesma ideia de união se apresenta no poema seguinte: "Ghimel". Só que não mais como a união das partes, e sim da multiplicação "A parte de / uma parte // em muitas / se reparte", pois "[...] nada se separa completamente do que o antecede. [...]" (PLOTINO, 2000, p. 64). Assim, Lucchesi empreende sua viagem, procurando o que está além da e na unidade:

Tem de haver algo além da Unidade. Do contrário, todas as coisas teriam permanecido potenciais, desprovidas de forma. Nenhum dos seres [do mundo intelectual] existiria se a Unidade permanecesse em Si mesma [...] também não existiria a pluralidade dos seres seguintes àqueles provenientes da Unidade e que pertencem à classe das almas. Do mesmo modo, o processo de exteriorização não poderia terminar no nível das almas, pois cada coisa deve produzir o que se segue a ela: é inerente à natureza de cada espécie produzir o que se segue a ela, bem como desenvolver-se a partir de um princípio (archê) central, como de uma semente, até chegar ao Mundo Sensível. (PLOTINO, 2000, p. 91; grifo do autor).

O que se segue no poema seguinte, "Dalet", perpassa essa mesma ideia advinda da unidade. Aqui o poeta nos apresenta a imagem do "rosto", onde "Mil / rostos // nas sombras / do nada // descansam / seus olhos", repetindo essas estrofes, só que alternando a segunda com a terceira, nos remetendo à ideia de 
contemplação, uma vez que os olhos descansam, param, focalizam em algo que nos é apresentado em seguida: "enquanto / mil pedras // enquanto / mil homens // se perdem / no abismo // por causa / de um rosto". A imagem que criamos é a de que "Mil rostos" transformam-se em "um rosto". A Unidade. Mas uma Unidade que soma, que nos leva ao além e ao que já passou. E nessa viagem, a procura constante é um objetivo. Enxergamos o princípio da matéria, nessa primeira parte, que leva o poeta a percorrer os caminhos do mundo físico e celeste.

Na segunda parte do livro, intitulada "Temporais", temos nove poemas, onde o poeta faz um passeio pelas fases do dia, levando-nos a interpretar o que parece ser o início de sua viagem: “No dorso / luminoso / da manhã // procuro // o espólio / de teu canto". Aparecem elementos que nos lembram a obra-prima de Dante. Estabelece-se, ainda, um diálogo com Ulisses, de Ítaca. Só que diferentemente de Ulisses, Dante viaja para a luz, a salvação; Ulisses, sem luz, termina naufragando. No dizer do próprio poeta, "O erro de Ulisses evidencia a finitude da razão. O naufrágio demonstra a altitude do herói e a soberania de Deus, impedindoo do sagrado." (LUCCHESI, 1994, p. 27). A procura de Lucchesi, nessa parte, está na matéria: “e assim / procuro a luz / que me confunde // e segue / essa procura / a procurar-me". Para o autor de Alma Vênus, as mudanças sofridas pela natureza correspondem a um caminho de buscas, desde os átomos até aquilo que não é matéria, numa relação de equilíbrio entre a natureza e seu espírito lírico. Assim, Lucchesi passeia pelos campos das ciências humanas, com e além da palavra, carregado de impressões dantescas. O poema seguinte, dessa mesma parte, é um chamamento ao Inferno e ao Paraíso da Comédia, ao empíreo e à barca de Caronte. Uma viagem à salvação, à Rosa celestial:

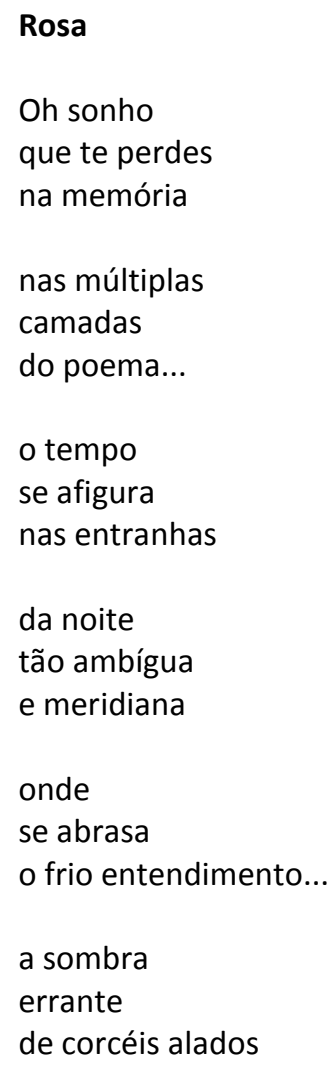




despenha-se
nos úberes
do mar
e afoga-se
no próprio
esquecimento
na selva
tenebrosa
dos sentidos...
oh rosa
imarcescível
e iridescente
se rútila
amanheces
no Ocidente
nas ínvias
solidões
meridionais
que o manto
que te adorna
não te engane:
além
das águas frias
do horizonte
(LUcCHESI, 2000, p. 35-36).

Aqui, percebemos que Lucchesi resgata da Divina Comédia o personagem Caronte, incumbido de conduzir as almas ao Inferno, em seu barco, através do rio Aqueronte. Tânia Franco Carvalhal vai dizer que:

[...] cada obra lê a tradição literária, prolonga-a ou rompe com ela de acordo com seu próprio alcance. A noção de originalidade, vista como sinônimo de "geração espontânea", criação desligada de qualquer vínculo com obras anteriores, cai por terra. (CARVALHAL, 2006, p. 63; aspas da autora).

Percebemos também essa influência de Dante em Lucchesi, nas duas primeiras estrofes do poema. Na primeira, associada à missão que Dante teria para escrever tudo que ali via; na segunda, as camadas que seu poema apresenta na divisão dos ciclos de cada reino. A "rosa", nesse poema, é "imarcescível / e iridescente". Há vida e cores. Uma luta por "mais" num universo dual que apresenta ao poeta os fascínios e terrores do mar. O poema leva o eu lírico a refletir, sem se deixar levar pela turbulência das emoções, e sem perder o brilho e a força de sua viagem, que se ilumina. "O Todo diferente emerge quando o homem descobre que pensa Deus, reivindicando para si a nostalgia do mais. [...]" (LUCCHESI, 1994, p. 50). 
Na penúltima parte de Alma Vênus, composta de oito poemas, a temática gira em torno da transitoriedade e brevidade da vida. Aqui Marco Lucchesi nos leva à proximidade entre a vida terrena e a celestial. Sua viagem se encaminha em direção ao transcendental, assim como Dante, que parte do Inferno ao Paraíso. O contato com o clássico se sobressai nessa parte quando o poeta traz o soneto, mesmo que subvertendo sua estrutura estrófica. Como se vê no poema que abre "Horizontes":

\author{
Dualismo \\ Teu rosto é claro se meu sonho é escuro, \\ só vens me visitar quando não quero, \\ andas perdido quando te procuro, \\ se mais confio em ti mais desespero. \\ Se buscas o passado sou futuro, \\ se dizes a verdade és insincero, \\ se temo tua face estou seguro, \\ se chegas ao encontro não te espero. \\ Bem sei que em nosso olhar refulge o nada, \\ que somos, afinal, a negação \\ mais funda, mais sombria e desolada. \\ Como lograr, meu Deus, reparação, \\ enquanto segues longe pela estrada, \\ de nossa irreparável solidão? \\ (LUCCHESI, 2000, p. 51).
}

A dualidade, presente nesse poema, dialoga de forma latente com Plotino, na busca da unidade. A Unidade constituída de outras unidades que formam o Uno. "Platão diz que o Uno não está fora de nada, mas está com todos os seres sem que eles percebam [...]" (PLOTINO, 2000, p. 136). Os opostos, nesse sentido, se somam "[...] quer as circunstâncias e condições sejam similares, quer sejam dissimilares [...] por outro lado, um resultado similar pode ser produzido por condições dissimilares. [...]" (PLOTINO, 2000, p. 160). Ao mesmo tempo em que se somam, tais partes não se encontram na natureza unidas, mas se complementam, assim como o bem precisa do mal e a luz da escuridão para existirem. A isso tudo Marco Lucchesi nos traz Dante, com A Divina Comédia, para dialogar com os opostos, quando tudo isso parte para o alto. Lucchesi une as partes opostas para formar um todo, buscando, inclusive, respostas para "nossa irreparável solidão".

Percebemos o quanto o poeta brasileiro está imbuído da poética de Dante. No primeiro verso de "Horizontes", as palavras "rosto" e "sonho" nos remetem ao real e ao inimaginável, ao tangível e ao intangível. Podemos associar a palavra "rosto" a Beatriz, e "sonho" ao mundo eterno. E também as oposições em todo o poema podem ser correlacionadas ao Inferno e ao Paraíso.

Dante nos diz, no último canto do Paraíso:

\footnotetext{
A auréola, da primeira refletida, tal como à minha vista ressurgia, quando sobre ela um pouco foi detida

um rosto humano ali me parecia ter instilado em sua irradiação;
} 
e, pois, todo para ela me volvia.

[...]

eu me sentia ante a visão divina:

e buscava aprender como essa imagem

na auréola se estampava, fidedigna.

[...]

Aqui findou, sem força, a fantasia:

(ALIGHIERI, 1984, p. 561-562).

Assim, o poeta florentino encerra sua viagem quando sua visão termina.

Na última parte, "Altitude", constituída de dez poemas, Lucchesi atinge o alto, o empíreo do Paraíso de Dante. Há poemas que fazem referência direta e indireta ao poeta florentino: "Vigília", "A contra-flor", "cristo", "rosto", "beatrizes", "rosa". Alguns poemas trazem referências a pensadores e personagens, como "pedros", vascos", “quixotes", “Gama”, "Platão”, "giocondas" “Teilhardiana”, “Messias". Enxergamos nesses personagens a natureza da busca do conhecimento.

No poema seguinte, temos:

Nuvens
Poço
esquecido
lívido
lume
da espera
e o sonho
de Platão
céu
acima
límpido
e claro
(LUCCHESI, 2000, p. 68).

Toda uma imagem filosófica de Platão é referendada, neste poema, por Marco Lucchesi. Temos, aí, a imagem de dois mundos, o tangível e o intangível, presente também na ideia de Dante sobre o Inferno e o Paraíso. Os versos que se seguem no poema nos trazem a mesma, ou quase, imagem do Paraíso dantesco. As palavras "lume", "límpido" e "claro" carregam a claridade do Paraíso, bem como sugerem os versos "céu / acima", em direção à luz. O poema remete à altitude, elevação, desde o seu título até o último verso. É brilho e espiritualidade. Diríamos que Lucchesi uniu perfeitamente Platão e Dante numa Unidade poética. É nessa parte que se atinge o apogeu da viagem lucchesiana, chegando-se "'a alma Vênus', o coração, a fundir novamente todas as formas a uma única luz, a convergir a matéria e o espírito numa só ordem." (ANDRADE, 2012, p. 111; aspa do autor), do "Poço / esquecido" ao "céu / acima", clara representação da viagem dantesca. E o próprio Lucchesi nos diz em A paixão do infinito que "Beatriz encontra-se na parte alta da Rosa. 
O grau de afastamento é sem termo. Trata-se do processo de acréscimo, poderosamente elaborado, entre os céus que despem raios e trovões [...] e o vasto abismo dos mares onde se perde o olhar. (LUCCHESI, 1994, p. 70)".

Nessas águas, vistas por olhos atentos e de viajante, Lucchesi celebra a eterna busca pelo conhecimento. E, voltando a Dante, o poeta de Alma Vênus nos afirma sobre o fascínio por essa busca: “O canto XXXI do Paraíso celebra a iminência do Retorno. O sentimento do Retorno. A ilimitada paixão do Retorno." (LUCCHESI, 1994, p. 67). Uma viagem sem fim. Uma busca por mais.

\section{Considerações finais}

Podem ser constatados, nesse artigo, os aspectos da obra prima de Dante Alighieri em Alma Vênus. A relação de Lucchesi com A Divina comédia nos permitiu encontrar meios de entender sua lírica, e de como esse clássico é revisitado pelo escritor carioca em sua construção poética.

Percebemos que a obra lucchesiana, vasta em seus significados, é uma oceano de múltiplos caminhos e é muito importante na poesia contemporânea brasileira, já que possui um viés representativo da metafísica. O diálogo com a filosofia, a consciência do poeta no trabalho com a palavra, versos enxutos e que dizem muito, além do diálogo com a tradição épica, são alguns dos aspectos relevantes da obra desse escritor.

Dessa forma, acreditamos ter conseguido elucidar algumas possibilidades de interprateção da obra de Marco Lucchesi e sua relevância para a literatura brasileira, levando em conta um de seus pontos-chave: o diálogo com o épico dantesco.

\section{Referências bibliográficas}

ALIGHIERI, Dante. A divina comédia. Trad. Cristiano Martins. Belo Horizonte: Itatiaia, 1984.

ANDRADE, Alexandre de Melo. Alma Vênus, de Marco Lucchesi: em busca do paraíso (im)perdido. In: Texto Poético. Revista do GT Teoria do Te xto Poético (ANPOLL). v. 8, n. 12, 2012.

CARVALHAL, Tânia Franco. Literatura comparada. 4 ed. São Paulo: Ática, 2006.

LUCCHESI, Marco. Poemas reunidos. Rio de Janeiro: Record, 2000. A paixão do infinito. Niterói: Clube de Literatura Cromos, 1994.

Ficções de um gabinete ocidental. Rio de Janeiro: Civilização Brasileira, 2009.

MARTINS, Cristiano. Vida atribulada de Dante Alighieri. In: ALIGHIERI, Dante. A divina comédia. Trad. Cristiano Martins. Belo Horizonte: Itatiaia, 1984. p. 23-97. 
MELLO, Ana Maria Lisboa de. A poesia metafísica no Brasil. In: [Org.]. A poesia metafísica no Brasil:

Percursos e Modulações. Porto Alegre: FAPA - Faculdade Porto-Alegrense, 2009. p. 11-34.

PLOTINO. Tratados das Enéadas. Trad. Américo Sommerman. São Paulo: Polar Editorial, 2000.

PROENÇA FILHO, Domício. Poesia brasileira contemporânea: multiplicidade e dispersão. In: [Org.].

Concerto a quatro vozes. Rio de Janeiro, São Paulo: Ed. Record, 2006. p. 7-18.

VILLAÇA, Antônio Carlos. Marco Lucchesi: Cultura e sensibilidade. In: LUCCHESI, Marco. A paixão do infinito. Niterói: Clube de Literatura Cromos, 1994. p. 15-20. 